\title{
Features of the development of gifted children at the initial school stage
}

\section{Belova Elena, Psychological Institute of Russian Academy of Education, Moscow}

\section{Introduction}

The change in the social situation of a child's development after entering school, the restructuring of his entire lifestyle are associated with great mental stress, creating risks in revealing his abilities and talents.

Prevention and overcoming risks in the development of gifted first-graders are possible only by creating a developing educational environment that provides safe conditions for the development and creative self-realization of gifted students. An analysis of Russian and foreign studies $[1,2,3]$ has shown that socio-psychological factors (features of the relationship with the participants of the educational process), characteristics of the educational process (goals, tasks, workload), and internal risk factors have the greatest impact on the psychological safety of the younger student.

On the grounds of revealed insufficient scientific investigation of the internal risk factors problem of the educational environment in the first class, the study was aimed at analyzing the characteristics of the emotional and motivational sphere of children with signs of giftedness at the initial school stage.

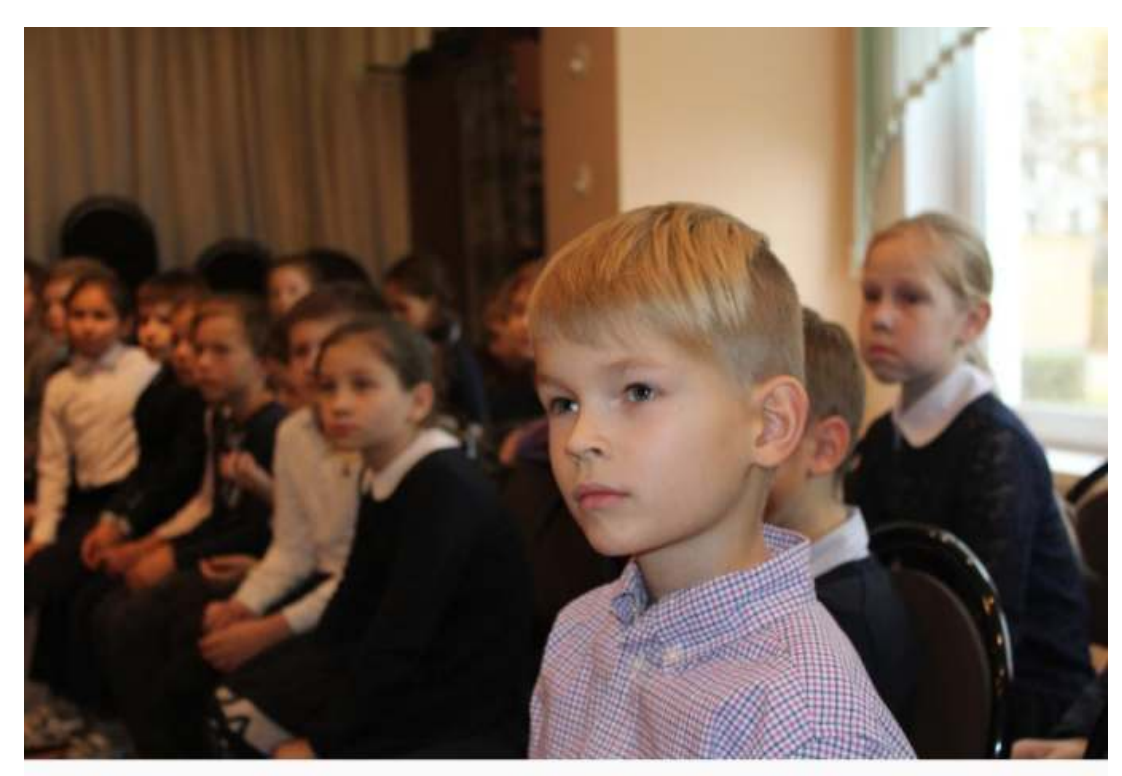

\section{Sample}

59 children of 7-8 years were examined. They studied in classes, where the program of creative interdisciplinary education (N.B.Shumakova [2]) was implemented. The program was focused on the capabilities and needs of children with signs of general mental giftedness. The highly professional teachers worked in the classes. They have extensive experience in elementary school, showing goodwill, validity and flexibility in communicating with children.

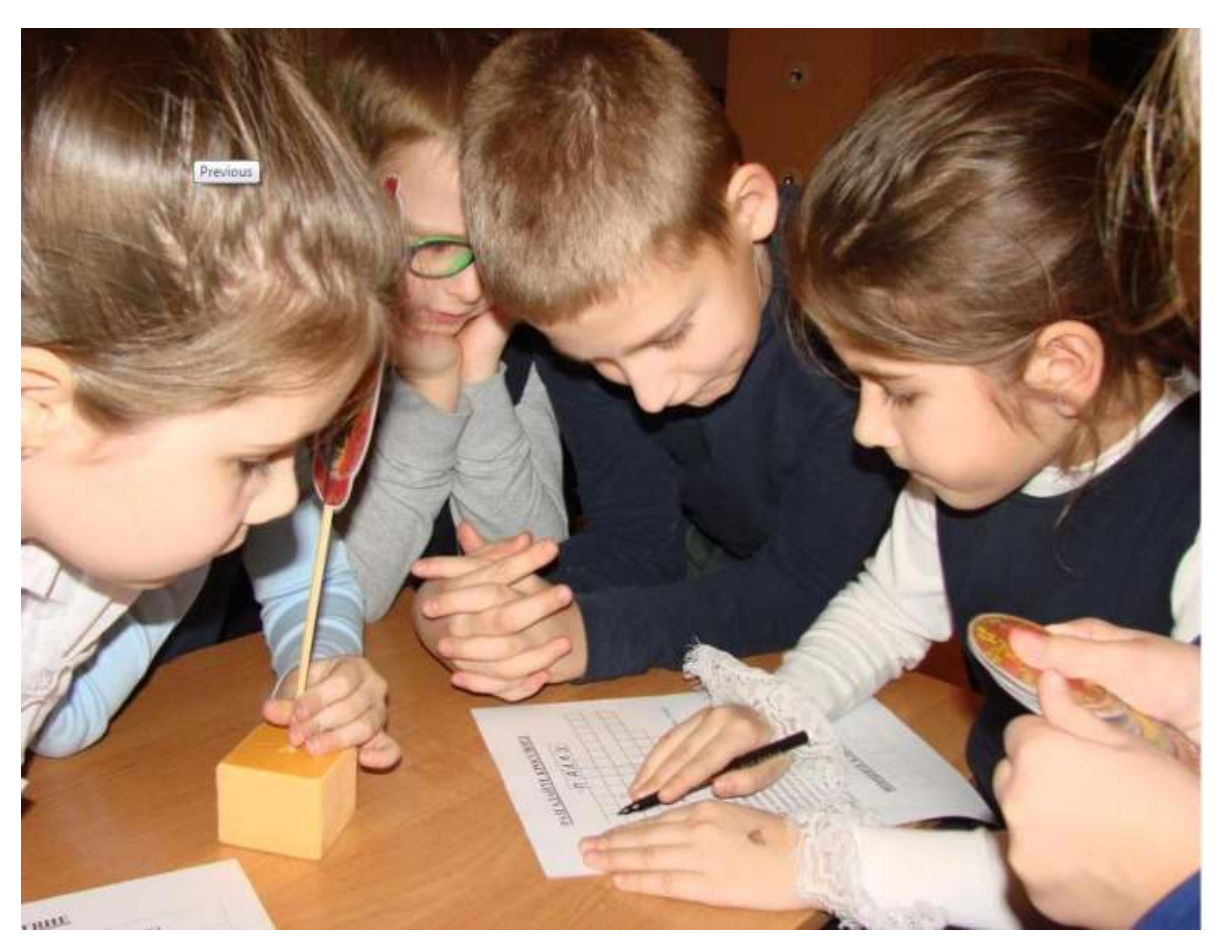

\section{Method}

Method of express diagnostics of intellectual abilities (MEDIS form A); modification of the method of L.A.Yasyukova "Color Associations", observation of children behavior; conversation with children, tutors and teachers; analysis of children creative products (paintings, stories etc. ), methods of qualitative and quantitative data processing

\section{The main results}

More than $80 \%$ of children revealed a high / above average level of intellectual development, signs of general mental giftedness. It was found that they have a positive attitude towards school and a desire to learn. At the same time, many of them need emotional support from adults, which makes them calm and balanced.

Development difficulties have been identified in some first-graders (difficulties of correct speech, attention, self-organization, signs of self-doubt, anxiety).

It was found that the high cognitive motivation of first-graders with signs of giftedness is combined with a declared interest in playing. Providing an opportunity to realize high cognitive activity and creative potential of gifted first-graders not only in learning, but also in playing games, as well as psychological and pedagogical support of their learning and development process are necessary conditions for successful disclosure of their giftedness, overcoming difficulties and risks.

Comparison of the upper and lower quartiles of the sample allowed us to identify individual differences in the development of children (see Figure).

First-graders with a high level of intellectual development and signs of intellectual talent (upper quartile of the sample) at a statistically significant level surpass their peers (lower quartile of the sample) in an effort to be active and initiative in cognition. At the same time, they are more sensitive than peers (differences at the level of a tendency) are characterized by increased sensitivity in relationships with adults, the need for emotional support.

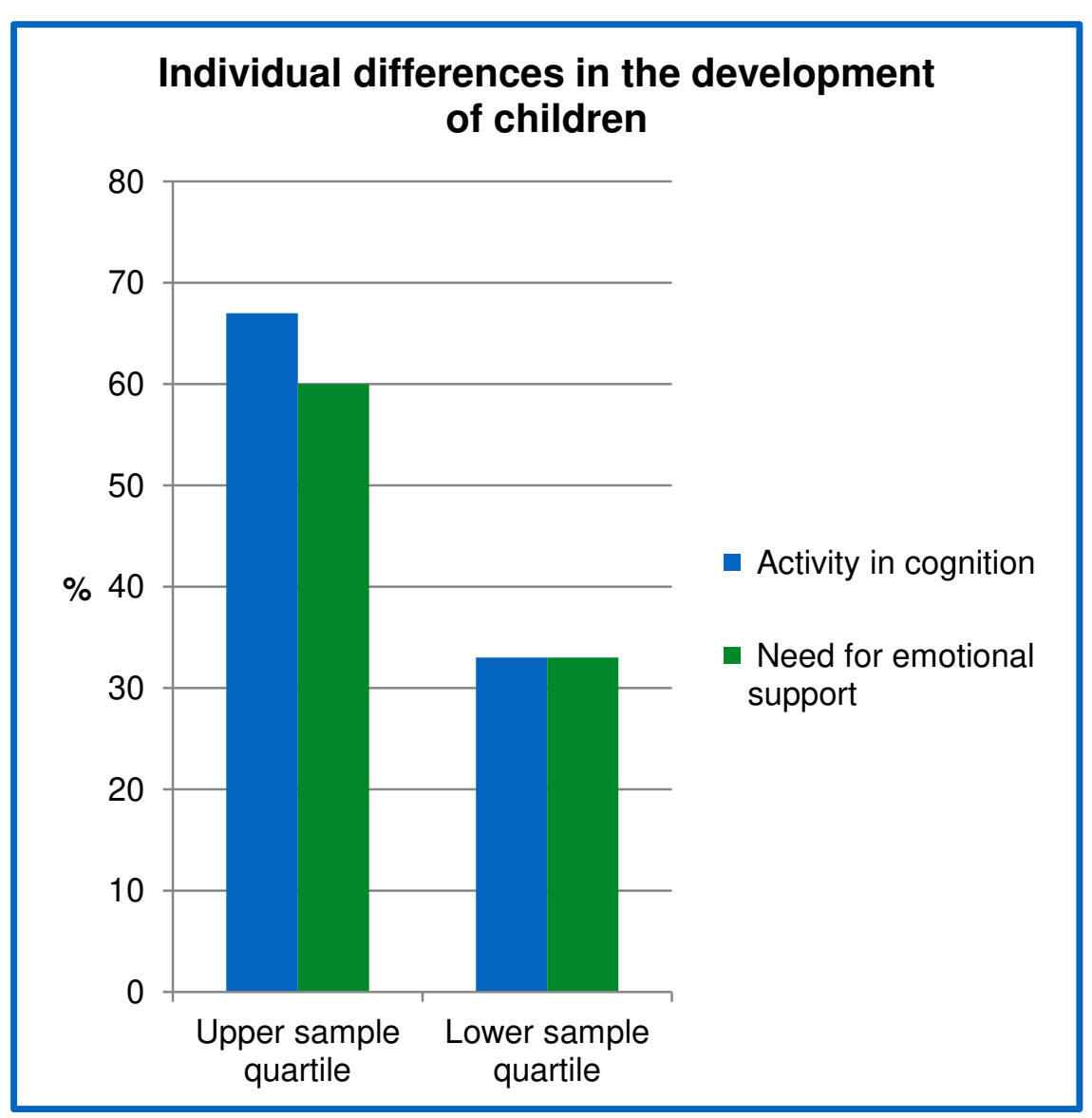

\section{Conclusion}

The results of the diagnostics of the intellectual, emotional and personal development of children with signs of giftedness at the beginning of their schooling determine the need for psychological and pedagogical support of their learning and development process. Timely assistance to them in adapting to schooling, building an individual trajectory for the development of each child from the first months of attending school contributes to the realization of his abilities and talents.

\section{References}

1. Monks, F. J., Ypenburg, I. (2011). Hoogbegaafdheid bi kinderen [Giltedness in children]. Amsterdam: Boom. interdisciplinary education for children and of creative with different types and levels of giftedness // Psychology of giftedness and creativity: / Larionova L. Psychology A.I.(Ed.). M., SPb.: Nestor History. P. 253-268. (in Russian)

3. Smutny J.F., Walker S.Y., Honeck E.I. (2016) Teaching Gifted Children in Today's Preschool and Challenging Children Ages 4-9. Free Spirit Publishing. 